\title{
STRUKTUR CERITA DAN NILAI PENDIDIKAN CERITA RAKYAT DI KABUPATEN KEBUMEN SEBAGAI MATERI AJAR SASTRA DI SEKOLAH MENENGAH PERTAMA
}

\author{
Eprini Endah Sari, Andayani, Budhi Setiawan \\ Universitas Sebelas Maret \\ Surel: epriniendahsari@student.uns.ac.id
}

\begin{abstract}
This research aims to describe: (1) contained structure in Kebumen folklore;
(2) the educational value found in Kebumen folklore; (3) the relevance of educational value on Kebumen folklore with literary learning materials in junior high school. This research includes qualitative research using case study (observation and interview) and analyzing several documents in the object form of folklore study in Kebumen regency related with interview result with resource persons related to folklore, and result of interview with teacher and student. Data analysis techniques using interactive model analysis techniques namely data reduction, presentation, and withdrawal of conclusions or verification.The results of this research are: (1) the story structure that contained in the three folklore in Kebumen Regency includes (a) themes, (b) characters and characterization, (c) background, (d) plot, and (e)the message of the story; (2) the educational values that contained in three Kebumen Regency folklore include (a) the value of social education, (b) the value of moral education, (c) the value of religious education, (d) the value of custom/traditional education, and (e) the value of heroic education; (3) the relevance of educational value to folklore with literary learning materials in junior high school according to the criteria of Basic Competence and Keynote Competence and contains a moral value in it.
\end{abstract}

Keywords: structural, educational value, learning materials

ABSTRAK: Penelitian ini bertujuan untuk mendeskripsikan: (1) struktur yang terdapat pada cerita rakyat di Kebumen; (2) nilai pendidikan yang terdapat pada cerita rakyat di Kebumen; (3) relevansi nilai pendidikan pada cerita rakyat di Kebumen dengan materi pembelajaran sastra di SMP. Penelitian ini termasuk penelitian kualitatif yang menggunakan strategi studi kasus (observasi dan wawancara). Teknik analisis data menggunakan teknik analisis model interaktif yakni reduksi data, penyajian, dan penarikan kesimpulan atau verifikasi.Hasil penelitian ini sebagai berikut: (1) struktur cerita yang terdapat pada ketiga cerita rakyat di Kabupaten Kebumen meliputi (a) tema,

(b) tokoh dan penokohan, (c) latar, (d) alur, dan (e) amanat; (2) nilai-nilai pendidikan yang terdapat pada ketiga cerita rakyat di Kabupaten Kebumen meliputi (a) nilai pendidikan sosial, (b) nilai pendidikan moral, (c) nilai pendidikan agama, (d) nilai pendidikan adat/tradisi, dan (e) nilai pendidikan kepahlawanan; (3) relevansi nilai pendidikan pada cerita rakyat dengan materi pembelajaran sastra di SMP sesuai dengan kriteria kompetensi dasar dan kompetensi inti serta mengandung nilai-nilai moral di dalamnya.

Kata Kunci: struktural, nilai pendidikan, materi pembelajaran

\section{PENDAHULUAN}

Sastra merupakan salah satu jenis warisan budaya bangsa yang harus dikembangkan dan dilestarikan. Horace (dalam Rokhmansyah, 2014: 8) menjelaskan bahwa fungsi karya sastra yakni 'dulce et utile' yang berarti kata 
dulce berarti indah dan utile berarti berguna. Artinya, sastra tidak hanya sekadar menampilkan keindahan tetapi juga memberikan kebermanfaatan dalam kehidupan. Pengarang dalam menciptakan sebuah karya sastra bebas menuangkan ide dan gagasannya sehingga terciptalah suatu karya sastra yang indah dan mengandung nilai-nilai kehidupan. Bahasa yang digunakan dalam karya sastra itu sendiri mengandung nilai-nilai estetik sehingga sebuah keindahan sebuah karya sastra semakin terlihat.

Sastra memiliki manfaat yang sangat besar dalam kehidupan karena karya sastra digunakan sebagai hiburan, renungan, bahasan pelajaran, dan media komunikasi simbolik. Karya sastra yang ada di Indonesia meliputi puisi,prosa, cerita rakyat, dan drama (Rokhmansyah, 2014: 13). Cerita rakyat merupakan salah satu karya sastra yang perlu diketahui oleh masyarakat karena dalam cerita rakyat memiliki nilai-nilai moral yang sangat banyak dan baik untuk diterapkan di dalam kehidupan sehari-hari. Gausal (2015) menjelaskan bahwa cerita rakyat adalah cerita yang hidup dan berkembang di tengah-tengah masyarakat, selain itu disampaikan dari mulut ke mulut dan pada dasarnya disampaikan oleh seseorang pada orang lain melalui penuturan lisan maupun tulisan.

Pada era modern ini, cerita rakyat di kalangan masyarakat sudah mulai punah karena perkembangan teknologi yang sudah semakin maju. Minat masyarakat akan membaca buku cerita rakyat sudah mulai pudar. Hampir setiap anak jarang sekali membaca buku cerita rakyat setelah mereka menganal teknologi seperti, gadget, televisi, film, dan internet. Mereka sudah mulai terpengaruh dengan adanya teknologi yang modern sehingga generasi muda kurang minat untuk mengapresiasi cerita rakyat yang ada di daerahnya. Kurangnya minat masyarakat akan cerita rakyat membuat mereka tidak akan mengetahui bahwa di daerahnya pun memiliki cerita rakyat yang tidak kalah menarik dari cerita rakyat daerah lain. Hal tersebut sejalan dengan pendapat Firdaus, dkk (2013: 39) bahwa banyak masalah yang berhubungan dengan cerita rakyat karena kurangnya pengetahuan dan minat masyarakat terhadap cerita rakyat yang disebabkan oleh kemajuan teknologi. 
Hal tersebut apabila dibiarkan akan merusak nilai-nilai moral masyarakat, sehingga perlu adanya penanaman moral pada generasi muda. Salah satu upaya untuk mengatasi hal tersebut dengan menanamkan nilai-nilai pendidikan dengan cara memperkenalkan cerita rakyat kepada generasi muda. Dalam cerita rakyat terdapat banyak nilai-nilai yang dapat merubah perilaku generasi muda menjadi lebih baik lagi. Cerita rakyat memiliki nilai-nilai pendidikan dan pesan moral yang dapat dilihat dari setiap tokoh cerita tersebut.

Kabupaten Kebumen merupakan salah satu tempat yang berada di Jawa Tengah. Tidak hanya terkenal akan tempat wisata dan makanan khasnya, tetapi Kabupaten Kebumen juga memiliki beberapa cerita rakyat yang memang belum diketahui oleh banyak orang. Kabupaten Kebumen memiliki khasanah budaya yang mengandung nilai pendidikan yang perlu dilestarikan. Hal tersebut dikhawatirkan jika budaya zaman dahulu akan pudar selaras dengan perkembangan zaman. Cerita rakyat di Kabupaten Kebumen yang diambil dalam penelitian ini berjumlah 3 cerita rakyat dari kawasan barat hingga timur. Cerita yang dikaji peneliti antara lain; (1) Legenda Gombong, (2) Raden Kamandaka (Lutung Kasarung), dan (3) Babad Kebumen.

Cerita rakyat di Kabupaten Kebumen dapat dihubungkan dengan materi pembelajaran Bahasa Indonesia di SMP khususnya sastra, karena terdapat di dalam Kompetensi Dasar Kurikulum 2013. Cerita rakyat di Kabupaten Kebumen banyak mengandung nilai-nilai pendidikan yang dapat mengubah generasi muda menjadi lebih baik lagi di kehidupan bermaysrakat. Sebelum mengetahui nilai pendidikan di dalam sebuah cerita rakyat, langkah awal yang harus dilakukan adalah memaparkan cerita rakyat tersebut dengan menggunakan pendekatan analisis struktural. Hal tersebut sejalan dengan pendapat Teeuw (2015: 106) bahwa pendekatan analisis struktural bertujuan untuk membongkar dan memaparkan secermat, seteliti, mendetail dan mendalam mungkin keterkaitan dan keterjalinan makna menyeluruh. Kajian struktural meliputi tema, alur, tokoh dan penokohan, latar, dan amanat. Setelah memaparkan kajian struktural, dapat diketahuilah nilai-nilai pendidikan yang terdapat pada cerita tersebut karena nilai pendidikan dapat diketahui melalui setiap tokoh pada cerita tersebut. 


\section{METODE PENELITIAN}

Penelitian ini menggunakan metode deskriptif kualitatif dengan menelaah isi dari cerita rakyat yang berasal dari Kabupaten Kebumen. Strategi dalam penelitian adalah studi kasus dengan menganalisis isi terhadap dokumen dengan hasil wawancara serta hasil observasi. Teknik pengambilan subjek penelitian yang digunakan adalah purposive sampling. Sumber data dalam penelitian ini antara lain, informan, tempat, dan dokumen. Informan dalam penelitian ini adalah juru kunci dan masyarakat yang mengetahui cerita rakyat di Kabupaten Kebumen, guru mata pelajaran Bahasa Indonesia, dan peserta didik kelas VII. Tempat yang dilakukan dalam penelitian ini di Desa Jatijajar, Gombong, Kutowinangun, SMP Negeri 3 Gombong, dan SMP Negeri 4 Gombong. Dokumen yang menjadi sumber data dalam penelitian ini antara lain: sumber tertulis dari ketiga cerita rakyat Kabupaten Kebumen, hasil wawancara dengan infroman, dan Silabus. Teknik pengumpulan data dilakukan dengan observasi, wawancara, dan dokumen. Observasi dalam penelitian ini dilakukan dengan mengamati objek kajian cerita rakyat yang berhubungan dengan tempat atau lokasi tersebut. Peneliti melakukan wawancara dengan juru kunci, sesepuh, masyarakat setempat, guru mata pelajaran Bahasa Indonesia, dan peserta didik Sekolah Menengah Pertama (SMP). Validitas data dilakukan dengan triangulasi sumber dan triangulasi metode. Teknik analisis data menggunakan analisis interaktif antara lain: reduksi data, paparan data, dan penarikan kesimpulan/verifikasi.

\section{HASIL PENELITIAN DAN PEMBAHASAN}

Penelitian ini bertujuan untuk menjawab permasalahan (1) bagaimana struktur pada cerita rakyat di Kabupaten Kebumen; (2) bagaimana nilai pendidikan yang terdapat pada cerita rakyat di Kabupaten Kebumen; dan (3) bagaimana relevansi nilai pendidikan pada cerita rakyat di Kabupaten Kebumen dengan materi pembelajaran sastra di SMP.

\section{Kajian Struktural Cerita Rakyat di Kabupaten Kebumen}


Cerita rakyat di Kabupaten Kebumen merupakan cerita yang belum diketahui banyak orang sehingga perlu dilestarikan. Adapun cerita rakyat yang digunakan antara lain: (1) Legenda Gombong, (2) Raden Kamandaka (Lutung Kasarung), dan (3) Babad Kebumen. Cerita rakyat tersebut merupakan cerita yang dapat mendidik generasi muda karena mengandung nilai-nilai pendidikan yang dapat diterapkan di kehidupan sehari-hari. Sebelum menemukan nilai-nilai pendidikan yang ada dalam cerita rakyat, langkah awal yang harus dilakukan adalah menganalisis struktural terlebih dahulu agar makna dari unsur-unsur cerita rakyat dapat dipahami dan dinilai.

Berdasarkan hasil analisis struktur, unsur-unsur yang terdapat pada ketiga cerita rakyat di Kabupaten Kebumen antara lain: (1) tema, (2) tokoh dan penokohan, (3) latar(setting), (4) alur, dan (5) amanat. Hal tersebut dijelaskan oleh Nurgiyantoro (2007: 37) bahwa analisis truktural dapat dilakukan dengan mengidentifikasi, mengkaji dan mendeskripsikan fungsi dan hubungan antarunsur fiksi yang bersangkutan, seperti bagaimana keadaan peristiwa-peristiwa,plot, tokoh dan penokohan, latar, sudut pandang, dan lain-lain sehingga masing-masing unsur itu dapat menunjang makna keseluruhan. Sejalan dengan pendapat Sunata (2014) menjelaskan bahwa analisis struktural merupakan salah satu kajian kesusastraan yang menitikberatkan pada hubungan antarunsur instrinsik pembangun karya sastra. Ketiga cerita rakyat tersebut dianalisis menggunakan kelima unsur, berikut hasil analisis:

Pertama, cerita rakyat Legenda Gombong. Tema dari cerita Legenda Gombong adalah perjuangan untuk hidup tentram dan damai. Dilihat dari tokoh yang bernama Kyai Giyombong ingin menyelamatkan rakyatnya dari Kompeni Belanda. Tokoh dan penokohan dalam cerita antara lain: (a) Kyai Gombong Wijaya atau Kyai Giyombong (peduli terhadap sesama); (b) Kyai Gajahnguling (tegas, konsisten); (c) Kertopati (keras kepala, kurang tegas); (d) Suroyudo (patuh, kurang tegas); (e) Suropati (patuh, kurang tegas); dan (f) Semi (cantik, kemayu). Latar atau setting yang terdapat pada cerita rakyat tersebut antara lain: (a) latar tempat (dukuh Giyombong, Benteng Van Der Wick, bukit Indrikulo, dukuh Dapur, tepi sungai, dekat titian bambu, di bawah pohon besar yang rindang, titian 
sungai, di bawah pohon bambu ampel pinggir sungai, sebelah barat jembatan kali Kedung Ampel, daerah Kemit, dan dukuh Romakamal); (b) latar waktu (pada masa perjuangan Pahlawan Diponegoro); (c) latar sosial (saling tolong menolong, peduli terhadap sesama). Alur yang terdapat dalam cerita rakyat Legenda Gombong merupakan alur maju. Hal tersebut diceritakan pada awalnya kedatangan Kompeni Belanda di daerah Gombong hingga daerah Gombong sudah aman, tentram, dan damai. Amanat yang terkandung dalam cerita tersebut adalah janganlah melalaikan tugas yang telah diamanahkan kepada kita karena orang lain merasa bahwa kita mampu untuk menjalankan tugas tersebut.

Kedua, cerita rakyat Raden Kamandaka (Lutung Kasarung). Tema yang terdapat pada cerita tersebut adalah perjuangan untuk mendapatkan cinta sejati. Dilihat pada tokoh bernama Raden Kamandaka yang berjuang untuk mendapatkan wanita impiannya, ia rela melakukan apa saja demi mendapatkan wanita yang sudah diidam-idamkan untuk dijadikan sebagai pendamping hidup. Tokoh dan penokohan dalam cerita antara lain: (a) Banyak Cokro atau Raden Kamandaka (tampan, gagah, sopan, bijaksana); (b) Dewi Ciptoroso (peduli kepada orang lain, baik hati, menerima apa adanya); (c) Prabu Siliwangi (bijaksana, tidak pilih kasih atau adil); (d) Patih Reksonoto (baik, penyayang, patuh); (e) Adipati Kanandoho (penyayang, over protektif, egois, angkuh); (f) Ki Ajar Wirangrong (jiwa sosial tinggi, suka menolong, tidak sombong); (g) Banyak Ngampat atau Silihwarni (patuh, penyayang, santun); (h) Rekajaya (jiwa sosial tinggi, penolong, baik hati); (i) Mbok Kertosoro (baik, jiwa sosial tinggi); (j) Raden Prabu Pule Bahas (jahat, licik, tidak peduli). Latar atau setting cerita Legenda Raden Kamandaka antara lain: (a) Latar tempat (Kerajaan Pajajaran, Gunung Tangkuban Perahu, Kadipaten Pasir Luhur, Kali Logawa, Taman Kaputren Kadipaten Pasir Luhur, Sungai, Desa Paniagih, Desa Karangkulas, Goa, dan Hutan Batur Agung); (b) Latar waktu (pada abad ke-40 pada masa Kerajaan Hindu yaitu Kerajaan Pajajaran); (c) Latar sosial (strata sosial, saling menghargai). Alur yang terdapat pada cerita adalah alur maju. Diceritakan sebelum Raden Kamandaka belum menemukan wanita yang diimpikannya hingga ia menemukan dan menikahi wanita yang sudah diimpikannya sejak lama. Amanat yang terkandung dalam cerita Legenda Raden 
Kamandaka adalah untuk mendapatkan sesuatu yang diinginkan, kita harus memperjuangkannya walaupun banyak sekali pantangan untuk mendapatkannya. Janganlah lupa untuk selalu berdoa kepada Yang Maha Kuasa agar dipermudah dalam mencapai keiingan tersebut.

Ketiga, cerita Babad Kebumen. Tema dari cerita Babad Kebumen tentang perjuangan untuk hidupnya. Dilihat dari tokoh utamanya yaitu Jaka Sangkrip yang berusaha untuk menyembuhkan penyakitnya dan mencari ilmu di sepanjang jalan yang dilaluinya hingga ia berusaha untuk mencari ayah kandungnya dengan berbagai cara. Tokoh dan penokohan pada cerita tersebut antara lain: (a) Jaka Sangkrip atau Surawijaya atau Honggawongsa (sabar, gigih, pantang menyerah, patuh); (b) Ki Rejatani (patuh, baik hati, peduli); (c) Dewi Nawangsasi (jail, peduli, suka menolong); (d) Pangeran Bumidirja atau Kyai Bumi (rendah hati, peduli); (e) Baginda Raja Sunan Amangkurat Agung (tidak adil, ingin menang sendiri); (f) Pangeran Puger (menepati janji, pemaaf). Latar atau setting yang terdapat pada cerita tersebut antara lain: (a) latar tempat (daerah Panjer, rumah Ki Demang Warganaya, depanpohon lo, sendang, Goa Menganti, hutan Moros, laut, Bulupitu, dan Banyumas); (b) latar waktu (pada masa Kerajaan Mataram); (c) latar sosial (berfikir dan bersikap, keyakinan). Alur yang terdpat pada cerita Babad Kebumen adalah alur maju. Dilihat dari peristiwa Pangeran Bumidirjo meninggalkan keluhuran dan kewibawaannya hingga memiliki cucu bernama Jaka Sangkrip yang berusaha untuk menyembuhkan penyakitnya dan mencari ayah kandungnya dengan berbagai cara. Amanat yang terkandung dalam cerita adalah jangan lupa untuk berdoa kepada Tuhan disetiap perjalanan hidup kita susah maupun senang, karena Tuhan akan memberikan pertolongan dan petunjuk dalam perjalanan kita.

\section{Nilai Pendidikan pada Cerita Rakyat di Kabupaten Kebumen}

Ketiga cerita rakyat di Kabupaten Kebumen mengandung nilai-nilai pendidikan yang dapat diterapkan dalam kehidupan sehari-hari. Hal tersebut sesuai dengan Kompetensi Dasar dan Kompetensi Inti yang terdapat pada Kurikulum 2013. Nasir (2016) mengungkapkan nilai pendidikan adalah batasan segala sesuatu yang 
mendidik ke arah kedewasaan, bersifat baik maupun buruk sehingga berguna bagi kehidupannya yang diperoleh melalui proses pendidikan. Nilai pendidikan dalam karya sastra meliputi nilai pendidikan religius, moral, sosial, nilai estetika, dan nilai adat/budaya (Purwaningtyastuti, 2014: 6). Berikut ulasan tentang nilai pendidikan yang terdapat pada ketiga cerita rakyat tersebut sebagai berikut:

Pertama, nilai pendidikan sosial. Nilai pendidikan sosial terdapat pada cerita Legenda Gombong yaitu dapat bersosialisasi dengan orang lain, seperti halnya Kyai Giyombong terlihat sangat akrab sekali dengan rakyatnya sehingga rakyatnya pun sangat mencintainya. Selain itu sikap saling tolong menolong dapat dilihat pada tokoh Kyai Giyombong meminta bantuan kepada pasukan Mataram untuk melawan Kompeni Belanda yang berada di sekitaran daerah Giyombong. Nilai pendidikan sosial pada cerita Raden Kamandaka (Lutung Kasarung) yaitu saling tolong menolong antar sesama seperti halnya yang dilakukan oleh tokoh $\mathrm{Ki}$ Ajar Wirangrong yang telah membantu Banyak Cokro untuk mendapatkan wanita yang diimpikannya. Nilai pendidikan sosial pada cerita Babad Kebumen yaitu peduli kepada orang lain. Hal ini dapat dilihat dari tokoh yang bernama Pangeran Bumidirja yang sangat mengayomi masyarakatnya. Selain itu saling tolong menolong, dilihat dari tokoh Ki Rejatani yang telah merawat Jaka Sangkrip hingga kesehatannya memulih kembali.

Kedua, nilai pendidikan moral. Nilai pendidikan moral yang terdapat pada cerita Legenda Gombong dapat dilihat dari tingkah laku seseorang. Pada cerita tersebut terdapat nilai negatif yang dapat dilihat dari tokoh Kertopati melawan Kyai Gajahnguling karena Kertopati telah melalikan tugasnya dan iapun tidak mengakui kesalahannya. Nilai pendidikan moral yang terdapat pada cerita Raden Kamandaka juga dapat dilihat dari tingkah laku seseorang. Terlihat dari tokoh Banyak Cokro yang sangat sopan kepada ayahnya ketika ia menolak untuk dijadikan seorang raja.

Ketiga, nilai pendidikan kepahlawanan. Nilai pendidikan kepahlawanan terdapat pada cerita Legenda Gombong. Hal ini dapat dilihat dari tokoh Kyai Giyombong yang ingin dukuh Giyombong bebas dari ancaman Kompeni Belanda sehingga ia berencana ingin meminta tolong kepada pasukan Mataram untuk 
membantunya melawan Kompeni Belanda yang berada di sekitaran daerah Giyombong.

Keempat, nilai pendidikan religius atau agama. Nilai pendidikan religius yang terdapat pada cerita Raden Kamandaka dapat dilihat dari tokoh Raden Kamanda yang pada saat itu bertapa untuk meminta petunjuk kepada Tuhan agar dapat dipertemukan dengan wanita yang sudah diimpikannya sejak lama. Nilai pendidikan religius pada cerita Babad Kebumen dapat dilihat dari tokoh Jaka Sangkrip yang selalu bertapa untuk mendapatkan pertolongan dan petunjuk dari Yang Maha Kuasa.

Kelima, nilai pendidikan adat atau tradisi. Nilai pendidikan adat atau tradisi pada cerita Raden Kamandaka dapat dilihat dari tokoh Raden Kamandaka yang menghormati dan menghargai tradisi yang terdapat pada desa Paniagih yaitu penyabungan ayam. Raden Kamandaka mengikuti perlombaan penyabungan ayam ketika ia tinggal di desa tersebut.

Relevansi Nilai Pendidikan pada Cerita Rakyat di Kabupaten Kebumen dengan Materi Pembelajaran Sastra di SMP

Pada kurikulum 2013 edisi Revisi 2016-2017 pada jenjang Sekolah Menengah Pertama (SMP) khususnya kelas VII semester genap terdapat Kompetensi Dasar (KD) dan Kompetensi Inti (KI) yang berkaitan dengan cerita rakyat yakni pada KD 3.15 dan KD 4.15. Diharapkan peserta didik mampu menguasai kompetensi dasar tersebut dengan menganalisis struktural yang terdapat pada cerita rakyat, meliputi tema, tokoh dan penokohan, latar atau setting, alur, dan amanat. Tidak hanya analisis struktural saja, tetapi peserta didik juga harus dapat menemukan nilai-nilai pendidikan yang ada di dalam cerita rakyat, meliputi nilai pendidikan sosial, nilai pendidikan moral, nilai pendidikan agama atau raligi, nilai pendidikan tradisi atau adat, dan nilai pendidikan kepahlawanan. Selain itu, peserta didik juga diharapkan mampu untuk menceritakan kembali isi dari cerita rakyat tersebut.

Cerita rakyat yang berjudul Legenda Gombong, Legenda Raden Kamandaka, dan Babad Kebumen dapat dijadikan sebagai materi pembelajaran sastra khususnya pada peserta didik kelas VII semester genap. Menurut informan, 
Kukuh Margi Mulyani dan Supriyo Budi Witoyo selaku guru Bahasa Indonesia di SMP bahwa ketiga cerita rakyat tersebut sudah memenuhi kriteria KI KD karena pada kurikulum 2013 peserta didik diharapkan mampu untuk menentukan unsur instrinsik seperti tema, tokoh dan penokohan, latar, alur, dan amanat. Jika sudah mengetahui analisis struktural maka peserta didik akan mengetahui nilai-nilai pendidikan yang terkandung di dalam cerita tersebut. Hal tersebut menunjukkan bahwa cerita rakyat di Kabupaten Kebumen dapat dijadikan sebagai materi pembelajaran khususnya sastra.

Ketiga cerita rakyat di Kabupaten Kebumen mengandung nilai-nilai pendidikan yang dapat diimplementasikan oleh peserta didik di kehidupan sehari-hari. Dapat dikatakan bahwa ketiga cerita rakyat tersebut sesuai dengan KD 3.15 yang menyangkut dengan nilai pendidikan. Menurut informan Kukuh Margi Mulyani, Ika Septiana Anggraeni, dan Sophiana Rahmania Kumalasari bahwa ketiga cerita rakyat tersebut menarik jika dijadikan sebagai materi pembalajaran karena mengandung nilai-nilai pendidikan yang dapat dilihat dari setiap tokohnya. Selain sesuai dengan Kompetensi Dasar dan Kompetensi Inti, ketiga cerita rakyat tersebut juga memperkenalkan kepada peserta didik bahwa di daerahnya pun memiliki cerita rakyat yang tidak kalah menarik dan mengandung nilai-nilai pendidikan. hal tersebut disampaikan oleh informan Kukuh Margi Mulyani selaku guru Bahasa Indonesia.

\section{SIMPULAN}

Berdasarkan hasil penelitian ini, dapat disimpulkan bahwa cerita rakyat Babad Kebumen, Legenda Gombong, dan Legenda Raden Kamandaka memiliki struktur yang dapat membangun cerita. Analisis struktur tersebut meliputi tema, alur, tokoh dan penokohan, latar atau setting, dan amanat. Analisis struktur bertujuan untuk memaparkan sedetail mungkin fungsi dan keterkaitan antar unsur-unsur di dalam karya sastra agar hubungan antarunsur tersebut dapat membentuk sebuah kemaknaan yang padu dan menyeluruh.

Ketiga cerita rakyat di Kabupaten Kebumen mengandung nilai-nilai pendidikan yang disampaikan secara tersirat melalui setiap tokohnya yang terdapat pada 
cerita rakyat tersebut. Nilai pendidikan yang terdapat pada ketiga cerita rakyat tersebut meliputi, nilai pendidikan sosial, nilai pendidikan moral, nilai pendidikan agama, nilai pendidikan adat atau tradisi, dan nilai pendidikan kepahlawanan.

Nilai yang paling menonjol pada ketiga cerita rakyat tersebut adalah nilai pendidikan sosial, dilihat dari setiap tokohnya yang peduli terhadap sesama.

Ketiga cerita rakyat tersebut jika direlevansikan dengan materi pembelajaran sastra di SMP sudah memenuhi kriteria Kompetensi Dasar dan Kompetensi Inti, karena ketiga cerita rakyat tersebut terdapat struktural, seperti tema, alur, latar, tokoh dan penokohan, dan amanat. Selain itu cerita tersebut mengandung nilainilai pendidikan dari setiap tokohnya yang dapat diimplentasikan oleh peserta didik di kehidupan sehari-hari. Ketiga cerita rakyat tersebut

\section{DAFTAR PUSTAKA}

Firdaus, M., Faizah Hasnah, \& Manaf, N. A. (2013). Cerita Rakyat Masyarakat Rambah Kabupaten Rokan Hulu Provinsi Riau. Jurnal Bahasa, Sastra dan Pembelajaran, 1 (2), 38-52.

Gausal, La Ode. (2015). Nilai-Nilai Pendidikan dalam Cerita Rakyat Sulawesi Tenggara Karya La Ode Sido. Jurnal Humanika, 15 (3).

Nasir. (2016). Nilai-Nilai Pendidikan dalam Nyanyian Rakyat Kau-Kaudara pada Masyarakat Muna. Jurnal Humanika. 16 (1).

Nurgiyantoro, Burhan. (2007). Teori Pengkajian Fiksi. Yogyakarta: Gadjah Mada University Press.

Purwaningtyastuti, R, dkk. (2014). Nilai Pendidikan dan Kesetaraan Gender dalam Novel. Surakarta: UNS Press

Rokhmansyah, Alfian. (2014). Studi dan Pengkajian Sastra; Perkenalan Awal terhadap Ilmu Sastra: Graha Ilmu.

Teeuw. (2015). Sastra dan Ilmu Sastra. Bandung: Pustaka Jaya. 